\title{
CIENCIA Y DOCUMENTACIÓN CIENTÍFICA EN LA PERIFERIA. LA ROYAL SOCIETY Y LA CREACIÓN DE LA OFICINA BIBLIOGRÁFICA MEXICANA (1895-1929)*
}

\author{
Mikel Astrain Gallart
}

Historia de la Ciencia. Universidad de Granada

\section{Guillermo Olagüe de Ros}

Catedrático de Historia de la Ciencia. Universidad de Granada.

Alfredo Menéndez Navarro

Profesor Titular de Historia de la Ciencia. Universidad de Granada.

\section{RESUMEN}

El presente trabajo pretende analizar y explicar la creación del Instituto Bibliográfico Mexicano en 1899. Este centro, iniciado y potenciado desde la iniciativa de la Royal Society y su International Catalogue of Scientific Literature, desarrolló toda una infraestructura documental a semejanza de las existentes en algunas naciones europeas en esos años (caso de Francia o el Imperio austríaco). El hecho de que fuera México el único país de habla hispana que participó en los congresos internacionales y en la confección del catálogo desde sus inicios propició el decidido apoyo gubernamental con la esperanza, además, de que sirviera de acicate para la creación de una estable comunidad científica. Ello no fue posible por la subordinación de la ciencia mexicana de aquel tiempo a la norteamericana y francesa y porque, como ya han puesto de manifiesto Polanco y Saldaña, los intentos de imitación u ósmosis de las periferías científicas a modelos centrales fracasaron en su mayor parte, a pesar de que, como en este caso, permitieron la conservación de algunos de los proyectos y su infraestructura.

\section{SUMMARY}

The present study aimed to analyse and explain the creation of the Instituto Bibliográfico Mexicano (Mexican Bibliographical Institute) in 1899. This centre was started and supported through initiatives taken by the Royal Society and its International Catalogue of Scientific Literature, and developed a complete documentation infrastructure, similar to those existing in some European countries at that time (e.g., France or the Austrian Empire). The fact that Mexico was the only Spanish-speaking country that

* Este trabajo ha contado con una Ayuda a la Investigación de la DGESIC (PB 98-1324). 
participated in international conferences or in the production of the catalogue from its onset led to strong support from the Government, who also hoped that it would spur the creation of a stable scientific community. This did not prove possible, because of the subordination of Mexican science to that of North America and France. Furthermore, as pointed out by Planco and Saldaña, attempts to imitate or to encourage osmosis from the scientific peripheries to central models mostly failed, although, as in this case, they allowed the preservation of some of the projects and infrastructure.

\section{LA MUNDIALIZACIÓN DE LA CIENCIA Y LAS COMUNIDADES CIENTÍFICAS PERIFÉRICAS}

La trasmisión de la ciencia moderna a regiones del planeta con un pasado colonial está recibiendo una creciente atención y análisis desde nuevas perspectivas y enfoques $^{1}$. El proceso de mundialización de la cultura occidental no ha sido un proceso lineal ni claramente secuenciado. La crítica al modelo de George Basalla (1967) sobre la difusión de la ciencia en tres etapas (de contacto, ciencia colonial y ciencia independiente) se ha basado fundamentalmente en la imagen unívoca y universal de la ciencia contenida en ella ${ }^{2}$. La unidireccionalidad y el necesario filtro metropolitano que conlleva esta concepción la ha hecho excepcionalmente débil desde el momento en que la historia de la ciencia (especialmente desde los case studies) se ha desarrollado en los ambientes académicos de las excolonias. Así pues, una creciente consideración de los contextos locales, independientemente de la estructura imperial, y una revalidación de los condicionantes geográficos y culturales, han supuesto una mirada crítica con un mayor grado de complejidad y de enfoque metodológico ${ }^{3}$.

1 Petitjean, P.; Jami, C.; Mopulin, A. M. (Eds.), (1992), Science and Empires. Historical Studies about Scientific Development and European Expansion, Dordrecht-Boston-London, Kluwer Academics Publishers [Boston Studies in the Philosophy of Science, Volume 136]. POLANCO, X. (Ed.) (1990), Naissance et development de la science-monde. Production et reproduction des communautés scientifiques en Europe et en Amerique Latine, Paris, Editions La Découverte-Counsil de l'Europe-UNESCO. LAFUente, A.; ElenA, A.; ORTEGA, M. L. (Eds.) (1993), Mundialización de la ciencia y cultura nacional, Madrid, Doce Calles. Sobre la configuración de las comunidades científicas latinoamericanas es de indispensable consulta la revista Quipu. Revista Latinoamericana de Historia de las Ciencias y la Tecnología, con algunos trabajos monográficos dedicados a las comunidades de Venezuela, México o Perú y relevantes discusiones metodológicas.

2 El artículo titulado «The Spread of Western Science» fue publicado en Isis, 156, 611-622. Un revisión y actualización por el propio autor a partir de las críticas recibidas puede verse en BASALLA, G. The spread of Western Science Revisited. En: LAfUENTE, A.; ElEnA, A.; OrTEGA, M. L. (Eds.) (1993), pp. 599-604.

3 Véase en este sentido la reflexión que para el campo de la investigación biomédica lleva a cabo Cueto, M. (1997), «Science under Adversity: Latin America Research and American Private Philanthropy, 1920-1960», Minerva, 35, 233-245. 
Como bien señalan Lafuente y Sala $(1989)^{4}$, dos son las debilidades fundamentales de la teoría de Basalla. Por un lado, la rígida diferenciación entre tradición y modernidad, que otorga a las metrópolis el protagonismo en la difusión mundial de la ciencia moderna. Por otro, el manejo del concepto de «primitivo»o «tradicional» contrapuesto a «moderno», que consagra una percepción del desarrollo científico como un proceso lineal y unívoco (tan utilizado en esquemas desarrollistas). Obviamente, y como bien apuntan los autores, el gran problema procede del riesgo que se asume al elaborar modelos.

El creciente interés por estudiar los procesos de difusión de la ciencia refleja la preocupación por resolver el conflicto generado por el aserto de que la ciencia es universal, mientras que las comunidades científicas son locales o nacionales. En este sentido, el presente trabajo intenta mostrar esta complejidad de intereses (personales, nacionales, académicos y políticos) y el recurso a la retórica de la universalidad de la ciencia ejemplificado en el campo de la documentación científica. La creación de la Oficina Bibliográfica Mexicana en 1900, ligada al ambicioso proyecto de edición de un Catálogo Internacional de Literatura Científica auspiciado por la Royal Society de Londres, cobra un renovado interés desde esta perspectiva. El recurso a la ciencia y a los modelos de la sociología positivista como elementos vertebradores de la sociedad mexicana durante el gobierno del general Porfirio Díaz (1876-1911), explican el apoyo proporcionado a dicha iniciativa en manifiesto contraste con la imagen de un país escasamente alfabetizado (13\% para los más optimistas historiadores), sin Universidad Nacional y con una absoluta dependencia técnica del extranjero para su explotación interior ${ }^{5}$.

\section{LOS «CIENTÍFICOS» Y LA CIENCIA MEXICANA DURANTE EL PERIODO DEL PORFI- RIATO (1876-1911)}

Durante la primera fase de vida independiente de los Estados Mexicanos, ninguno de los sectores políticos que pugnaron por el poder dispusieron de condiciones materiales y políticas que permitieran llevar a cabo sus proyectos respectivos de sociedad. Tanto liberales como conservadores recurrieron a la ciencia, aunque de forma con-

\footnotetext{
4 «Ciencia colonial y roles profesionales en la América española del siglo XVIII», Quipu, 6, 387403; pp. 388-389.

5 El caso de la construcción del ferrocarril es paradigmático. Fue construido fundamentalmente con capital, tecnología y técnicos foráneos. La oligarquía mexicana mantuvo una actitud exageradamente optimista con respecto a su capacidad transformadora que no se correspondió con la realidad. Activó la integración económica de México en la economía internacional (especialmente norteamericana) y sirvió para mantener al dictador en el poder. Simbólicamente, también, el inglés era el idioma utilizado, tanto en manuales, oficinas y en los propios talleres. ORTIZ HERNÁN, S. (1985), «La innovación ferroviaria en el México del siglo XIX», Quipu, 2, 59-85.
} 
trapuesta, como instrumento político. Mientras los liberales utilizaron el cultivo de las ciencias como base de una ideología opuesta al dogmatismo religioso y a la tradición política colonial, los conservadores lucharon por mantener sus privilegios despreciando de forma manifiesta el valor de la ciencia ${ }^{6}$.

En este período se registraron algunas excepciones al escaso desarrollo institucional de la actividad científica. Entre ellas destaca la creación de ciertas instituciones estatales, tales como el Instituto de Geografía y Estadística (1833) dedicado al desarrollo de estudios científicos, económicos y demográficos, el Banco de Avío (1830) y la Dirección de Industria (1842). Así mismo surgieron sociedades científicas, como la Academia de Medicina (1824), la Academia Farmacéutica (1838) o la Sociedades Mexicanas de Agricultura (1845) y de Geografía y Estadística (1850). Tales sociedades tuvieron, en general, una corta vida media con excepción de aquellas apoyadas en colectivos profesionales consolidados, caso de las médicas, o aquellas que contaron con un decidido respaldo estatal, caso de la geográfica ${ }^{7}$. De forma paralela, las publicaciones científicas tuvieron un azaroso devenir, salvo aquellas ligadas a dichas sociedades. Entre ellas cabe destacar el Boletín de la Sociedad Mexicana de Geografía y Estadística, creado en 1839, y principal órgano difusor de la ciencia mexicana ${ }^{8}$. En síntesis, una situación que muestra el acrecentamiento del hiato existente entre la ciencia americana y europea —eliminado en cierta manera durante el periodo colonial— 9 .

Una vez que el proyecto conservador, destinado a establecer un Imperio con el príncipe Maximiliano, fue derrotado militarmente, los liberales con Benito Juárez a la cabeza, restablecieron la República, iniciándose el proceso de pacificación y reorganización del país. Se formó un pacto político entre diferentes sectores de la sociedad sobre la base de modernizar la economía e impulsar la industrialización, estimulando las actividades económicas y científicas. La necesidad de un estado fuerte capaz, entre otras tareas, de garantizar la paz social, fue el caldo de cultivo de formas políticas autoritarias, que desembocaron en la dictadura del General Porfirio Díaz.

La filosofía positivista de Comte se introdujo en la enseñanza y en la política. El modelo de organización social propio del positivismo sirvió de referente en el nuevo proyecto de articulación social. De hecho, el grupo oligárquico que mantuvo a Porfirio Díaz en el poder tomó el nombre de los «científicos», apelativo aparecido por vez primera en un documento de 1892. En él se solicitaba la reelección del General Díaz

\footnotetext{
6 Moreno, R. (1986), Ciencia y revolución mexicana. En: Ensayos de Historia de la Ciencia y la Tecnología en México, México, UNAM, pp. 143-163.

7 SAldAÑA, J. J.; AZUELA, L. F. (1994), «De amateurs a profesionales. Las Sociedades científicas méxicanas del siglo XIX», Quipu, 11, 135-172. El trabajo incluye un listado completo de las sociedades científicas creadas durante el siglo XIX.

8 Ibidem.

9 Esta cuestión se discute en: SAgasti, F. R.; PAVEZ, A. (1989), «Ciencia y Tecnología en América Latina a principios del siglo XX: Primer Congreso Científico Panamericano»: Quipu, 6, 182-196; 192-193.
} 


\section{CIENCIA Y DOCUMENTACIÓN CIENTÍFICA EN LA PERIFERIA}

con argumentos clarificadores. Entre ellos destacaba el anhelo nacional de progreso intelectual y moral logrado a través «de esa fuerza mental que se transforma en inconmensurable fuerza física y que se llama ciencia» ${ }^{10}$. La conversión de la ciencia en un ingrediente de la lucha política hizo de ella no sólo la encarnación de la promesa ideológica de solucionar los problemas que afligían a la sociedad mexicana, sino un excelente escaparate para exhibir el progreso y el nivel de civilización obtenido.

Los sectores industriales y financieros fueron considerados motores del progreso material, a la vez que elementos claves en la neutralización de los conflictos sociales. Desde este punto de vista, la ciencia y la técnica adquirieron gran importancia, convirtiéndose en adalides de la modernización social. Junto al marchamo positivista, la apuesta por el desarrollo industrial y la modernización tecnológica exigió el concurso del capital extranjero. El Estado, no solamente facilitó la inversión foránea sino que ofreció condiciones preferentes a la mano de obra cualificada procedente del exterior $^{11}$. Paralelamente, se potenció la formación de academias y asociaciones de carácter científico: la Sociedad Mexicana de Historia Natural (1868), la Sociedad Científica Antonio Alzate (1884), o la Academia Mexicana de Ciencias Exactas, Físicas y Naturales (1895). También la participación en los congresos científicos, tanto en territorio nacional como en el extranjero, recibieron el estímulo estatal. En los dominios de la medicina, la botánica o la geología, se contribuyó extensamente al conocimiento del propio país ${ }^{12}$. Por el contrario, las ciencias aplicadas conocieron un desarrollo bastante limitado, tributario de la mencionada dependencia tecnológica y económica del exterior.

La organización de la enseñanza, especialmente en los niveles elemental y medio, ocupó un importante lugar en el debate nacional. El elemento central del nuevo sistema educativo fue la Escuela Nacional Preparatoria, que mantenía un sistema comtiano de clasificación de las ciencias e insistía sobre el papel del método experimental en su organización. Por contra, diversos autores han señalado la relegación de la cuestión universitaria del citado debate ${ }^{13}$. Cerrada desde la consecución de la independencia, en razón de su «naturaleza colonial», la Universidad fue considerada una

10 Tan inusitada apelación a la ciencia en un panfleto reeleccionista no podía escapar a la malicia de los opositores al dictador. Cfr. MORENO, R. (1986), p. 147.

11 ORTIZ HERNÁN, S. (1985), p. 77, muestra la participación mayoritaria de las potencias europeas y de los Estados Unidos en el desarrollo industrial mexicano. Como ya mencionamos, el protagonismo anglosajón se plasmó en el empleo del inglés como idioma de trabajo del propio personal de las compañías ferroviarias que operaron en esta época.

12 SALDAÑA; AZUELA (1994), p. 142-144. Este afán asociativo no fue exclusivo de la sociedad mexicana sino que se produjo en toda Latinoamérica. CAPEL, H. (1993), El asociacionismo científico en Iberamérica. La necesidad de un enfoque globalizador. En: LAFUENTE; ELENA; ORTEGA (Eds.), pp. 409-428.

13 MAYer, L.; ChAZARO, L. (1992), «La universidad en el último cuarto del siglo XIX: los silencios culturales», Quipu, 9, 327-347. Dumas; C. (1986), Justo Sierra y el México de su tiempo, 1848-1912, Vol. II, México, UNAM, pp. 245-247. MoRENO, R. (1986), p. 155. 
institución incapaz de dar cabida a los postulados modernizadores y positivistas. Como bien recordaba Justo Sierra ${ }^{14}$, Ministro de Instrucción Pública y responsable de su reapertura definitiva en 1910, la Universidad «era un cuerpo que había cesado de tener funciones adaptables a la marcha de la sociedad, por eso murió, por eso hizo bien el partido liberal en matarla y enterrarla» ${ }^{15}$. Una declaración que precedía a su definitiva «resurrección» radicalmente transformada.

Decenios de liberalismo y positivismo, no lograron disipar el conflicto social. En 1911 estalló la revolución. La lucha dio como resultado un cambio de rumbo político más acorde con las realidades internas y externas, mediante la formación de un estado liberal, democrático y burgués, de tendencia corporativa. Aunque los planteamientos e ideologías de las facciones más avanzadas no se hicieron realidad, es innegable que el proceso revolucionario cambió el país, que salió de la lucha más unificado, más democrático y más nacionalista. Para el cultivo orgánico y sistemático de la ciencia contemporánea este proceso de cambio fue su condición de posibilidad. Hasta los años 30 no se reconstruyó la vida científica y técnica de México. Ese fue el momento de reabrir el período de reindustrialización, en tanto que parte integrante de una política nacionalista de modernización, unida a la nacionalización de las explotaciones petrolíferas en $1938^{16}$.

\section{LA TRADICIÓN BIBLIOGRÁFICA MEXICANA Y LA ÉLITE PORFIRIANA}

La historiografía americana y americanista ha venido considerando a la pasada centuria, dadas las condiciones históricas y sociales de Hispanoamérica en general y de México en particular como el «siglo de oro» de la bibliografía mexicana ${ }^{17}$. Basta citar los nombres de Beristáin de Souza, García Icazbalceta o Nicolás León -todos ellos ampliamente estudiados (hagiografiados en mayor o menor medida) por los historiadores mexicanos-, y su obra impresa, para trazar un panorama de lo que significó la labor bibliográfico-histórica de este período ${ }^{18}$. En sintonía con el tradicional recurso a las bibliografías retrospectivas como elemento legitimador, se confeccionaron

14 Sobre este reconocido positivista, integrante del grupo de los "científicos" que apoyaron la dictadura porfirista, puede verse el excelente trabajo DUMAS, C. (1986), 2 vols., especialmente el volumen segundo.

15 Discurso de presentación ante el Congreso del Proyecto de Ley de creación de la Universidad Nacional, 1910. Tomado de MAYER, L.; CHAZARO, L. (1992), p. 342.

16 MoRenO, R. (1986), pp. 161-162.

17 MANTECON, J. I. (1962), «El primer Instituto Bibliográfico mexicano», Boletín Bibliográfico. Segunda época, 12, 3-17

18 Así lo explicitaba el propio Nicolás León en una Memoria leída ante el Congreso Nacional en 1900: "Aunque la bibliografía en México arranca en sus orígenes en el primer tercio del siglo XVIII puede decirse con toda justificación, que su desarrollo data del último tercio de la centuria cuya finalización celebramos". LEÓN, N. (1903) «La bibliografía en México en el siglo XIX»: Boletín del Instituto Bibliográfico Mexicano, 3, 5. Fue anteriormente publicado en el periódico El Tiempo Ilustrado, I, 1901, 1-3. 
los repertorios fundamentales que sistematizaron la producción intelectual de las prensas mexicanas desde su establecimiento, en 1539 , hasta el fin de la época colonial ${ }^{19}$.

No solamente floreció la literatura bibliográfica erudita e histórica. Durante el último tercio del siglo XIX y, especialmente, durante los años de gobierno liberal, el grupo de intelectuales porfiristas autodenominados «científicos» apoyaron decididamente la labor propagandista de la bibliografía ${ }^{20}$. De esta forma México se incorporó a la confección de bibliografías especializadas sobre las ciencias naturales, corriente que en Europa ya había adquirido una gran importancia. Baste mencionar en este sentido la ingente labor llevada a cabo por la Royal Society de Londres con la edición del Catalogue of Scientific Papers (1867-1925), o la confección iniciada en 1858 por Poggendorff del Biographiche-literariches Handwörterbuch ... ${ }^{21}$. Esta línea de trabajo se materializó en las obras de Manuel de Olaguíbel (1890) Memoria para una bibliografía científica del siglo XIX ${ }^{22}$, de Rafael Aguilar y Santillán Bibliografía Metereológica mexicana correspondiente al año de 1890 y Bibliografía geológica y minera de la República Mexicana $(1898)^{23}$ y del propio Nicolás León Biblioteca Botánica (1895) $)^{24}$, autores que, como veremos más adelante, jugaron un papel decisivo en el devenir del Instituto Bibliográfico.

Durante estos años se produjo la profesionalización de los estudiosos del libro y la reorganización de las bibliotecas. Simultáneamente se estaban gestando en Europa proyectos documentales tendentes a «universalizar» la información del quehacer científico mediante la confección de repertorios de actualidad, expresión de lo que se

19 Recientemente ha sido publicado por el propio Instituto de Investigaciones Bibliográficas un excelente catálogo de las obras mexicanas de la pasada centuria, CASTRO. M. A.; CURIEL, G. (coords.) (1997), Obras monográficas mexicanas del siglo XIX en la Biblioteca nacional de México: 1822-1900 (Acervo general), México, UNAM. Curiosamente, y como lo expresa el actual director del Instituto en el prólogo de la monografía, éste fue creado con objeto de trabajar en la bibliografía mexicana del siglo XIX, pero durante su breve vida realizó otros importantes trabajos dejando pendiente el que había sido el origen de su creación. Ibidem, p. 7.

20 Como ha señalado GonZALEZ, L. (1961), Fuentes de la historia contemporánea de México. Libros y folletos, México, El Colegio de México/FCE, p. XXXVI, "la sed de ciencia de los liberales dio origen a los primeros catálogos de libros científicos hechos en México".

21 MALClÉs, N. (1956), La bibliographie, Paris, Presses Universitaires de France, p. 91.

22 México, Oficina Tipográfica de la Secretaría de Fomento, 1889. Sólo se publicó la sección primera correspondiente a Botánica. Una década después, en colaboración con Enrique Iglesias, editó la Bibliografía científica del estado de México. Toluca, Oficina Tipográfica del Gobierno en la Escuela de Artes, 1899. Manuel de Olaguíbel murió al año siguiente.

23 La primera entrega de la bibliografía metereológica se publicó en: Memorias y Revista de la Sociedad Científica Antonio Alzate, IV (1890-1901), 265-276 y continuó en la misma revista hasta 1899. En cuanto a la geológica y minera estaba terminada en 1892 y continuó editándose en la Secretaría de Fomento con adiciones en 1908, 1918 y 1936.

24 El título completo de la obra es Biblioteca Botánico-mexicana. Catálogo bibliográfico, biográfico y crítico de autores y escritores referentes a vegetales de México y sus aplicaciones, desde la conquista hasta el presente. México, Oficina Tipográfica de la Secretaría de Fomento. La obra contiene más de mil fichas y sirvió al autor de pasaporte para ingresar en el Instituto Bibliográfico. 
ha venido en llamar el «movimiento documental contemporáneo». ¿Qué repercusión tuvieron estas iniciativas en México? ¿Cómo se plasmó la colaboración mexicana en los mismos? ¿Cómo se articuló esta participación en la política científica del porfiriato? Ciertamente, el grado de involucración en las iniciativas documentales europeas sitúan a México en una posición privilegiada en el concierto de las naciones de habla hispana, en abierto contraste con el parco desarrollo científico antes visto.

Del temprano conocimiento de las iniciativas documentales en tierras mexicanas son buena expresión las palabras de Jesús Galindo y Villa (1867-1937):

«... los hombres estudiosos se preocupan actualmente por unificar las clasificaciones, adelantándose a la idea de construir sobre bases firmes la bibliografía universal internacional, proyecto que abarque el conjunto de la producción científica literaria de todos los tiempos y todos los países, comprendiendo el inventario de los artículos contenidos en las revistas. A tal objeto tienden principalmente los trabajos del Instituto Internacional de Bibliografía, establecido en Bruselas, y los de la Sociedad Real de Londres»25.

Entre los dos grandes proyectos internacionales que coparon el panorama documental finisecular, el gobierno mexicano se decantó por su participación en el londinense, de carácter bastante más pragmático y técnico, manteniendo simplemente contactos informales e intercambio de publicaciones con el liderado por el legista belga Paul Otlet en Bruselas ${ }^{26}$.

\section{El PROYeCTO DE LA ROYAL SOCIETY DE LA ELABORACIÓN DEL INTERNATIONAL CA- TALOGUE OF SCIENTIFIC LITERATURE Y LA BIBLIOGRAFÍA EN MÉXICO}

Como hemos analizado en otro lugar ${ }^{27}$, la Royal Society promovió desde 1894 la creación de un repertorio bibliográfico de actualidad para las disciplinas de ciencias

25 «La Junta Nacional de Bibliografía Científica. Informe presentado a la Sociedad Alzate en la sesión del 11 de diciembre de 1898», Revista de la Sociedad Antonio Alzate, 5 (1899), 7-16.

26 De las relaciones entre ambas instituciones solamente hemos encontrado constancia en los archivos del envío por parte de la Oficina Internacional de Bruselas de un ejemplar de su Boletín, correspondiente al año 1898 "esperando estimular con ello el intercambio permanente de publicaciones". Archivo de la Biblioteca Nacional de México (en adelante A.B.N.), Fondo Universidad, Carpeta 32, Expediente 704. Distinto fue el caso de otros países latinoamericanos, como el chileno, vinculado al proyecto belga. OlagüE De Ros, G.; MEnÉndeZ NAvarro, A.; ASTRAin GAllart, M. (1998), «Internacionalismo científico y Latinoamérica: la participación de Chile en los proyectos europeos documentales contemporáneos (1895-1929)», Cronos, 1, 85-112.

27 OlagüE De Ros, G.; Menéndez Navarro, A.; Astrain Gallart, M. (1992), «La incorporación de España al "movimiento documental" europeo de principios de siglo: la contribución de la Academia de Ciencias Exactas, Físicas y Naturales de Madrid al International Catalogue of Scientific Literature (1904-1921) y la Unión Internacional Hispano-Americana de Bibliografía y Tecnología Científicas (1910)». Dynamis, 12, 225-261; OlagüE De Ros, G.; MenÉndeZ NAVARRo, A.; Medina DoMENECH, 


\section{CIENCIA Y DOCUMENTACIÓN CIENTÍFICA EN LA PERIFERIA}

básicas, una tarea que exigía de la activa colaboración internacional ${ }^{28}$. En 1894, el secretario de esta prestigiosa institución científica realizó un envío de invitaciones a las principales instituciones científicas y educativas del mundo. En su gran mayoría, estuvieron de acuerdo en la bondad de la idea y se declararon dispuestas a colaborar en el proyecto. La celebración en julio de 1896 de la primera Conferencia Internacional de Bibliografía en Londres, sentó las bases del funcionamiento del International Catalogue of Scientific Literature. La conferencia sancionó un organigrama basado en la creación de oficinas bibliográficas nacionales, encargadas de recoger la producción científica local, y remitirlas a la Oficina Central ubicada en la propia Royal Society ${ }^{29}$.

La única nación de habla hispana que aceptó este reto fue México. El Secretario de Justicia e Instrucción Pública del gobierno del General Porfirio Díaz, Joaquín Baranda $^{30}$, asumió la responsabilidad estatal en el proyecto, evidenciando la necesidad de prestar cobertura institucional al desarrollo del quehacer bibliográfico ${ }^{31}$. Baranda designó a Francisco del Paso y Troncoso delegado nacional en la conferencia de 1896. Del Paso se encontraba en esos momentos pensionado en Europa con objeto de reproducir y enviar a México los fondos archivísticos y bibliográficos, custodiados en el viejo continente, que interesaran a la historia de México $^{32}$.

R.; ASTRAIN GALlarT, M. (1997), «Internacionalismo y Ciencia. Las bases sociocientíficas del movimiento documental europeo», Dynamis, 17, 317-340.

28 Debemos recordar que la primera iniciativa de crear un repertorio universal de ciencias la tomó la Royal Society, tras la propuesta del secretario de la Smithsonian Josep Henry en la reunión mantenida en Glasgow por la Sociedad Británica para el Progreso de las Ciencias, en 1855, y se materializó en el Catalogue of Scientific Papers.

29 Una descripción detallada de la marcha de las conferencias y la diferente participación de los científicos, en RICHET, Ch. (1898), «Le project de la Société Royal de Londres et la classification décimale», Revue Scientifique, 9, 749-752; TAX CHOLDIN, M. (1978), «The Russian Connection": The Bureau of International Bibliography and the "International Catalogue of Scienctific Literature», The Journal of Library History, 13, 239-249.

30 Nacido en Campeche en 1840, estudió Jurisprudencia titulándose en 1862. Salió elegido diputado con el triunfo de la República y más tarde pasó al Senado. Durante la Presidencia de Manuel González fue nombrado Secretario de Justicia e Instrucción Pública. Destacado orador, fue miembro correspondiente de la Real Academia de la Lengua de Madrid. Murió en 1937 en la capital federal cuando ocupaba todavía el cargo de senador.

31 Según LAFUENTE, R. (1992), Un mundo poco visible: imprenta y bibliotecas en México en el siglo XIX, México UNAM-CUIB, p. 115.

32 Francisco del Paso y Troncoso (Veracruz 1842-Florencia 1916) fue director interino del Museo Nacional, presidente de la Comisión mexicana en la Expedición Histórico-Americana de Madrid. Salió de México el 3 de agosto de 1892 y permaneció en Europa hasta su muerte. Su principal misión consistió en la publicación del Sahagún, códice conservado en la Biblioteca Laurenziana de Florencia. Además estudió los códices matritenses de la Biblioteca de Palacio y de la Academia de la Historia. Zavala, Silvio (1938), Francisco del Paso y Troncoso. Su misión en Europa (1892-1916), México, Departamento Autónomo de Prensa y Publicidad. 
El primer informe que Del Paso y Troncoso rindió al gobierno mexicano sobre las cuestiones tratadas en la conferencia de Londres recomendaba, en consonancia con la resolución número 16 de la misma, la creación de una Oficina Bibliográfica Nacional Mexicana $^{33}$. En una carta posterior, remitida desde Florencia donde residía temporalmente, trasmitía al secretario Baranda su preocupación sobre la posibilidad de que la indecisión del gobierno y retraso en la creación de la oficina causara la exclusión de México del proyecto documental. La raigambre nacionalista de sus argumentos, que convertían la labor documental en publicista de la ciencia mexicana, resultaba manifiesta:

«La abstención se pudiera interpretar como una manifestación de impotencia... Es conveniente para la nación, a mi modo de ver, que mida sus propias fuerzas y aprenda a conocerse por lo que produce. Tal vez el ensayo de registrar nosotros mismos nuestra literatura científica nos dé la medida de lo que realmente valemos: si el trabajo es bueno, será para nosotros motivo de íntima satisfacción; si no lo fuere tanto, pondremos entonces el remedio y en un segundo ensayo recogeremos ya frutos más óptimos. A la vista salta que los hombres de ciencia tendrán estímulo tan luego como se convenzan de que sus producciones, si son estimables, no quedarán ignoradas del mundo civilizado, como ha sucedido hasta hace poco; y que sus nombres serán anotados en el mismo registro que contendrá los de los sabios más eminentes de ambos hemisferios: todos pugnarán por hacerse dignos de semejante honra, y no dudo que sus trabajos irán adquiriendo cada día más importancia...» ${ }^{34}$.

La argumentación de Del Paso se basaba en cuatro tipos de razonamientos: de cortesía, de decoro, de conveniencia y en última instancia de estímulo. De cortesía y decoro para el propio gobierno mexicano, ya que en la Conferencia habían estado representadas las naciones más cultas del mundo «civilizado» y el hecho de quedarse fuera del proyecto se podía entender como una manifestación de impotencia y falta de peso en el concierto internacional. Además, avisaba del peligro de caer en una cierta «tutela científica» ya que los responsables del catálogo recogerían de forma deficiente la producción científica mexicana. De conveniencia para la nación, que confrontaría de esta manera su potencialidad científica y su capacidad organizativa: «lo que realmente valemos». Y de estímulo para la comunidad científica, ya que la difusión internacional de sus logros, supondría un premio y reconocimiento del trabajo realizado por los investigadores.

El peso de los argumentos barajados convenció al gobierno mexicano, que volvió a depositar en Del Paso la representación mexicana para acudir al Segundo Congreso Internacional de Bibliografía a celebrar en Londres en 1898. Tras su celebración, Del Paso y Troncoso elaboró un plan de creación de una Junta Bibliográfica Nacional

33 A.B.N., Fondo Universidad, Expediente 1. Informe de Francisco del Paso, fechado en Oxford el 21 de agosto de 1896.

34 Carta de Francisco del Paso y Troncoso al Secretario de Instrucción Pública, A.B.N., Fondo Universidad, Exp. 561, fechado el 20 de noviembre de 1897. 


\section{CIENCIA Y DOCUMENTACIÓN CIENTÍFICA EN LA PERIFERIA}

Mexicana, a imitación (como él mismo declaraba en su misiva) de la establecida en el Imperio Austriaco. Así, las labores de coordinación que en el país centroeuropeo se encomendaban a la Biblioteca Imperial, en México serían asignadas a la Biblioteca Nacional. El plan fue comunicado al Secretario de Relaciones Exteriores y, posteriormente, al de Instrucción Pública. Este último, Joaquín Baranda, fue nombrado Presidente de la Junta Nacional y, por encargo suyo, el Director de la Biblioteca Nacional, José María Vigil, cursó invitaciones a las principales sociedades científicas del país para que nombraran representantes a la misma. Las sociedades elegidas fueron: la Academia de Ciencias Exactas, Físicas y Naturales - correspondiente de la de Madrid-, la Sociedad Mexicana de Geografía y Estadística, la Sociedad de Historia Natural y la Academia Nacional de Medicina. Los representantes designados por éstas fueron, respectivamente, el Dr. Jesús Sánchez, Angel Domínguez, Jesús Galindo y Villa y el Dr. Porfirio Parra ${ }^{35}$.

En cuanto a la distribución teórica de las materias que cada organismo debía de supervisar se acordó adjudicar matemáticas, astronomía, meteorología, física, cristalografía y química a la Academia de Ciencias; geografía física y matemáticas a la Sociedad Geográfica; mineralogía, geografía, zoología y botánica a la Sociedad de Historia Natural y finalmente las materias de anatomía, fisiología, patología, antropología, psicología, farmacología y bacteriología (esta última se incorporó en el último momento al catálogo) a la Academia de Medicina. Se establecía, además, la necesidad de contar con la cooperación de otras instituciones de carácter científico y humanístico.

Acorde con el diseño expuesto, la Junta Nacional de Bibliografía Científica Mexicana quedó formalmente constituida el 5 de diciembre de 1898, estableciendo su sede en los locales de la Biblioteca Nacional. Su primera iniciativa consistió en integrar en el proyecto a otras pujantes academias científicas, entre ellas, la prestigiosa Sociedad «Antonio Alzate» y la de Ingenieros ${ }^{36}$. Así mismo, comunicó a los gobernadores de los diferentes estados mexicanos la necesidad de crear Juntas locales, integradas por tres individuos, que velasen por el registro de las publicaciones científicas en sus territorios. El plan de Del Paso preveía la creación y consolidación de la Junta en un Instituto Bibliográfico Mexicano. De hecho, la composición de la primera incluyó desde sus inicios a destacados bibliógrafos. Tales eran los casos de Rafael Aguilar y Santillán, Luis González Obregón, Jesús Galindo y Villa y el propio Tron-

35 Todos ellos tenían en común haber asistido a la Escuela Nacional Preparatoria, como ya vimos, embrión pedagógico de las doctrinas positivistas y cientificistas en México e institución mimada por la élite porfirista. El propio Porfirio Parra (1854-1912) llegó a ocupar su dirección.

36 La Sociedad «Antonio Alzate» nombró representante a su Secretario Perpetuo, el ingeniero Rafael Aguilar y Santillán (1863-1940), especialista en mineralogía y geología. Por parte de la Sociedad de Ingenieros se comisionó al también ingeniero Agustín Aragón (1870-1954), especialista en geografía que jugó un importante papel político en la administración del gobierno de Díaz. Destacado positivista, acabó en el bando opositor al general. DICCIONARIO Porrúa. Historia, Biografía y Geografía de México. $5^{a}$ Ed., Ed. Porrúa. 
coso. En abril de 1899 se acordó la definitiva creación del Instituto que quedó formalmente constituido en mayo de ese mismo año ${ }^{37}$. Su funcionamiento, claramente detallado en sus bases y reglamento, era similar al de una academia, con reuniones mensuales — celebradas el primer lunes de cada mes-. La presidencia del Instituto correspondía al Secretario de Instrucción Pública, encomendándose la vicepresidencia y dirección del mismo al Director de la Biblioteca Nacional. El ejemplar del Reglamento que nosotros hemos manejado corresponde al publicado como apéndice en la Bibliografía jurídica mexicana, del jurista Manuel Cruzado ${ }^{38}$. En ella se incluye el nombramiento de este destacado abogado mexicano como miembro del mismo así como un listado de todos sus socios. En las primeras sesiones se acordó ampliar el número de sus miembros, incorporándose en octubre el erudito Nicolás León, asî como al propio Manuel Cruzado y al presbítero Vicente de Paula Andrade, entre otros. Llama la atención la escasa representación de científicos sensu estricto, ya que de sus 25 componentes, sólo ocho (tres ingenieros y cinco médicos) no pertenecían al campo de las humanidades (entre los que destaca el peso de los legistas) ${ }^{39}$.

La labor del Instituto sobrepasó con creces las funciones de oficina correspondiente con el lnternational Catalogue. El Instituto, con un patrón similar al de los países adscritos al otro gran proyecto documental del momento, liderado por el Instituto de $\mathrm{Bi}$ bliografía de Bruselas, estimuló la confección de bibliografías nacionales en los campos humanístico y científico. De esta manera se declararon corresponsales del Instituto las ya mencionadas Juntas locales y se crearon comisiones especializadas:

\author{
I.- Ciencias Eclesiásticas \\ II.- Filosofía y Pedagogía \\ III.- Jurisprudencia \\ IV.- Ciencias Matemáticas, Físicas y Naturales \\ V.- Ciencias Médicas \\ VI.- Bellas Artes y Artes y Oficios \\ VII.- Filología y Bellas Artes \\ VIII.- Historia y Ciencias Auxiliares (Bibliografía)
}

\footnotetext{
37 Según al acta de la sesión del 29 de mayo de 1899, el Ministro Baranda declaraba formalmente instalado el Instituto nombrando Presidente Honorario al General Porfirio Díaz. A.B.N., Fondo universidad, expediente 685 .

38 El Reglamento fue publicado como folleto independiente en ese mismo año de 1899 por la Oficina Tipográfica de la Secretaría de Fomento.

39 Para Ignacio Mantecón, la creación del Instituto Bibliográfico representa la plena integración de México en el movimiento documental, que priorizaba la confección de instrumentos bibliográficos de actualidad en las distintas disciplinas científicas. Esta labor recopiladora no se circunscribía a los libros y folletos sino que se ampliaba a las publicaciones periódicas (MANTECóN, J.I. (1961), p. 8).
} 
Esta clasificación respondía a la confeccionada por el belga Namur, y fue la utilizada por el Director de la Biblioteca Nacional, José María Vigil, para la catalogación de los fondos de la misma durante esos años ${ }^{40}$.

Las Juntas Locales fueron nombradas con las instrucciones enviadas por el Instituto el 31 de diciembre de 1899. Estuvieron compuestas por ternas de reconocidos eruditos y su trabajo resultó bastante dispar. La Junta Local del estado de Yucatán, por ejemplo, escribió haciendo saber que había tenido su primera reunión, pero planteaba dudas sobre los materiales a catalogar y las reglas a seguir. Algunos Estados, entre ellos Veracruz, contestaban diciendo que «no había movimiento científico publicista en sus territorios». Otros estados sí enviaron listados de obras. Así, una clara excepción fue el caso de Primo Feliciano Velázquez, quien en su calidad de Secretario de la Junta Local de Bibliografía Científica de San Luís de Potosí, publicó en 1901 una Bibliografía Científica Potosina. Algunas Juntas llegaron incluso a insertar anuncios en la prensa local pidiendo la colaboración de los autores, debido al «escaso o nulo» movimiento científico ${ }^{41}$.

Otra tarea del Instituto, promovida por Nicolás León, fue el desarrollo del artículo octavo de las bases constitutivas del Instituto: «Dará noticias, hasta donde sea posible, de las obras relativas a México fuera del país por autores extranjeros». Para ello, se propuso la publicación de un Anuario y la concesión en exclusiva de su venta a un librero europeo, que a cambio, pagaría el envío de catálogos de obras y de venta de libros que contuvieran temas mexicanos. Además, propuso la suscripción a las publicaciones Börsenblatt für der deutschen Buchchandel (Leipzig), Polybiblion y Bibliographie de la France (París), Notes and Queries (Londres) y Library Journal (órgano de la Asociación de bibliotecarios norteamericanos). La exclusividad en el comercio de las publicaciones realizadas por el Instituto fue finalmente rechazada por atentar contra los principios liberales del librecambismo propugnados por la élite porfirista.

40 CATÁLOGOS de la Biblioteca Nacional formados bajo la dirección de José María Vigil, 12 vols., 1889-1991. José María Vigil (Guadalajara 1829-México D.F. 1909), estudió Jurisprudencia y se afilió tempranamente al Partido Liberal, al que defendió desde las columnas de prensa. En 1869 fue nombrado magistrado en la Corte Suprema de Justicia. En noviembre de 1880 fue nombrado Director de la Biblioteca Nacional. Después de estudiar los sistemas de clasificación se decidió por los del bibliotecario belga Paul Namur. Catalogó más de diez mil obras. IGuiNIZ, J.B. (1943), «José María Vigil, humanista e historiador». En: Disquisiciones bibliográficas, México, Colegio de México, pp. 78-90. También véase: La Biblioteca Nacional de México, Ibidem, pp. 269-292.

41 En el prólogo de la obra dice el autor «Este trabajo fue presentado en abril de 1899 a la Junta Local de Bibliografía Científica de San Luis de Potosí, la que tuvo por bien hacerlo suyo y lo remitió a la Junta Nacional de México, para cooperar a los fines de la Royal Society of London. El autor fue Secretario de la Junta Local por nombramiento del Superior Gobierno del Estado y es ahora socio correspondiente del Instituto Bibliográfico Mexicano». La bibliografía no siguió normas internacionales de catalogación. La correspondencia entre las Juntas locales y la Oficina Central pueden verse en A.B.N., Fondo Universidad, Expediente 4 (I), 1899. 
El plan del Instituto resultaba a todas luces muy ambicioso. Partiendo de la colaboración con el International Catalogue de la Royal, se pretendía elaborar una bibliografía nacional, tanto histórica como corriente y especializada, y recoger todas las obras escritas por mexicanos y de autores extranjeros sobre México. Sin duda, este plan respondía a la corriente más positivista («cientificista») y nacionalista de la intelectualidad mexicana, que veían en la recuperación del acervo documental mexicano una reafirmación de su propia identidad nacional.

Además de a los intereses nacionales, la labor del Instituto respondió a las propias ambiciones de sus protagonistas. La presencia mayoritaria de humanistas explica que solamente llegaran a publicarse algunas series retrospectivas, no prosperando ninguna de las iniciativas bibliográficas de actualidad al margen de los envíos a la oficina londinense ${ }^{42}$. Además, la mayor parte de las fichas bibliográficas recopiladas correspondían a trabajos ajenos a las disciplinas científicas básicas, por lo que resultaron inservibles para los propósitos del proyecto londinense.

El Instituto suscribió, como era obligatorio, diversas series del International $\mathrm{Ca}$ talogue. La amplitud de la suscripción — cinco series anuales, cada una compuesta por diecisiete entregas - y la puntualidad en su abono resultan llamativas para un país como México. Por ejemplo, España, incorporada en 1904 al proyecto, sólo suscribió una serie por razones económicas, cuyo pago estuvo sometido a continuas demoras $^{43}$. Las cinco suscripciones mexicanas fueron destinadas a las siguientes instituciones: Secretaría de Despacho de Instrucción Pública y Bellas Artes, Escuela Nacional Preparatoria, Escuela Nacional de Ingenieros, Escuela Nacional de Medicina y Biblioteca Nacional.

La dimisión de Joaquín Baranda llevó a la presidencia del Instituto a Justino Fernández y, posteriormente, en 1905, al activo y polifacético Justo Sierra, quien no creyó prioritaria la labor de esta Institución y no asistió nunca a sus reuniones. Desde 1902 se habían adjudicado 500 pesos mensuales para los gastos del Instituto con los

\footnotetext{
42 La bibliografía del siglo XVI ya había aparecido en la obras de García Icazbalceta. El Instituto, por su parte, editó los estudios Ensayo Bibliográfico del siglo XVII de Vicente de Paula Andrade y la Bibliografía mexicana del siglo XVIII de Nicolás León, además de reservarse la compilación de la correspondiente al siglo XIX. Por otro lado, editó la ya citada Bibliografía jurídica mexicana y la continuación de la Bibliografía geológica y minera de Rafael Aguilar y Santillán. Miembro ilustre de la generación de los «científicos», Aguilar se formó en las escuelas Nacional Preparatoria y Nacional de Ingeniería. Su obra presenta por orden alfabético de autores las obras de mineralogía, minería, geología, metalurgia, legislación y estadística mineras de México, aparecidas desde 1556 hasta 1896. Una iniciativa que tiene un claro precedente en nuestro país en el repertorio elaborado por los ingenieros de minas Eugenio Maffei y Ramón Rúa Figueroa: Apuntes para una biblioteca española de libros, folletos y artículos, impresos y manuscritos, relativos al conocimiento y explotación de las riquezas minerales y a las ciencias auxiliares, 2 vols., Madrid, Imp. J. M. Lapuente, 1871-72.

43 Olagüe De Ros, G.; Menéndez Navarro, A.; Astrain Gallart, M. (1992), 225-261, pp. $227-230$..
} 


\section{CIENCIA Y DOCUMENTACIÓN CIENTÍFICA EN LA PERIFERIA}

que se atendieron los pagos para las principales publicaciones bibliográficas, incluido su boletín. Esta publicación periódica fue encargada a Nicolás León y de ella se editaron once números hasta 1908. La actividad del Instituto languideció desde 1902, y cayó en el olvido definitivamente en 1908, con el fallecimiento de José María Vigil - a la sazón director de la Biblioteca Nacional_, y la supresión de la dotación presupuestaria $^{44}$.

Durante los años 1916 a 1919 se creó la Escuela Nacional de Bibliotecarios y Archivistas, a partir de un proyecto del propio Nicolás León respaldado por el nuevo director de la Biblioteca Nacional, Luis Manuel Rojas ${ }^{45}$. En 1956, la Universidad incorporó la carrera de Biblioteconomía a la Facultad de Filosofía y Letras y en 1959 se restableció el Instituto Bibliográfico, convertido desde 1967 en Instituto de Investigaciones Bibliográficas, dependiente de la Universidad Nacional Autónoma de México, y que incluye a la Biblioteca y Hemeroteca nacionales.

\section{LA INTRODUCCIÓN DE LA CLASIFICACIÓN DECIMAL UNIVERSAL EN MÉXICO}

El proyecto documental auspiciado por el Instituto de Bibliografía de Bruselas hizo de la difusión internacional de la C.D.U. unos de sus pilares básicos. Como hemos tenido ocasión de explorar en otros trabajos, la incorporación de este sistema de indización a las bibliotecas, archivos y publicaciones periódicas, estuvo sometido a diversos avatares ligados a intereses profesionales ${ }^{46}$.

La vinculación mexicana al proyecto continental se limitó al intento del instituto bruselense de conseguir la aceptación de la introducción en los archivos y bibliotecas mexicanos. El conocimiento de la C.D.U. fue facilitado por la participación en la Exposición Universal de París de 1900. El presidente de la Comisión Mexicana para dicho evento, el ingeniero Fernando Ferrari Pérez, publicó varios artículos de contenido bibliográfico, en general afines a la posturas defendidas por el Instituto de Bruselas. Su intención era dar a conocer y vulgarizar esta «útil e ingeniosa» clasificación. Proponía, a su vez, clasificar con este sistema todos los libros y folletos que la

\footnotetext{
44 Mantecón, J. I. (1961), p. 16.

45 Proyecto para el establecimiento de una Oficina Central de Bibliografía. Archivo General de la Nación, Instrucción Pública y Bellas Artes, leg. 44, exp. 10, 1-11.

46 OlagüE De Ros, G.; Astrain Gallart, M.; Menendez Navarro, A.; Medina Domenech, R. (1995) La introducción de la Clasificación Decimal Universal en España (1896-1923) En: CARRILLO, J.L.; OlagüE De Ros, G. (eds.), Actas del XXXIII Congreso Internacional de Historia de la Medicina (Granada-Sevilla, 1-6 de septiembre de 1992, Sevilla, Imp. Pinelo, Pp. 115-1130. OLAGÜE DE Ros, G.; MenÉndez Navarro, A.; Medina Domenech, R.; ASTRAin GAllart, M. (1995), La recepción en España de las corrientes documentales europeas contemporáneas. En: ARQUIOLA, E.; MARTÍNEZ-PÉREZ. J. (eds.) Ciencia en expansión: Estudios sobre la difusión de las ideas científicas y médicas en España (siglos XVIII-XX). Madrid, Editorial Complutense, pp. 370-384.
} 
República Mexicana se disponía a exhibir en la magna exposición. Ferrari, en la presentación se declaraba ferviente partidario de este sistema decimal:

\footnotetext{
«Por mi parte, hace años que lo uso ventajosamente, tanto en el arreglo de mi biblioteca como en el de los numerosos recortes de periódicos y notas importantes que conservo» ${ }^{47}$.
}

Esta convicción le llevó a traducir y publicar un año más tarde, también en la imprenta de la Secretaría de Fomento, una versión íntegra de la clasificación de Melvil Dewey, probablemente la primera publicada en México ${ }^{48}$. Además, se realizaron intentos de introducir la decimalización en su biblioteca y archivo.

Como es lógico, también en el seno del Instituto Bibliográfico surgió la discusión sobre la bondad y utilidad del sistema decimal a la hora de clasificar las fichas bibliográficas. El propio Instituto de Bruselas cursó una nota al recién creado Instituto Bibliográfico mexicano intentando inclinar sus preferencias hacia el sistema decimal, decididamente más universalista ${ }^{49}$. Para discutir este tema se convocó una reunión específica en los locales de la Biblioteca, a la cual, por motivos médicos, no pudo asistir el socio Jesús Galindo y Villa. El representante de la Sociedad de Historia Natural envió una nota exponiendo su postura y proponiendo finalmente la creación de una Comisión de Clasificación:

\footnotetext{
«Es mi concepto que no debemos aceptar en principio el sistema decimal, sino condicionalmente (subrayado en el original). Hay serias objeciones: $1^{\circ}$. que no es un sistema científico sino arbitrario (así lo dice Funck-Brentano, archivero bibliotecario de la Biblioteca del Arsenal, $2^{\circ}$. cada uno de nosotros necesita poseer la clave, el texto de la clasificación, $3^{\circ}$. a pesar de que hace furor este sistema en el mundo científico, la Conferencia Internacional de Bibliografía de Londres, pudiendo aceptarlo, no lo hizo ${ }^{50}$ ».
}

Galindo y Villa publicó en 1901 un interesante ensayo sobre la clasificación de los conocimientos humanos y la bibliografía, en el que repasaba las principales clasificaciones universales, incluidas la de Dewey, la de Bruselas y la adoptada por la Royal Society. En su análisis, tras insistir en el desacuerdo entre la convención londi-

47 CLASIFICACIÓN Decimal de Melvil Dewey, La. Tres Artículos. México, Oficina Tipográfica de la Secretaría de Fomento, 1899. Contiene la traducción de tres trabajos publicados en la Revue Scientifique, a saber SAuvage, E. «La clasificación Bibliográfica Decimal»; RICHET, Ch. «La Clasificación Decimal y el proyecto de la Sociedad Real de Londres» y «La CLASIFICACIÓN decimal de Melvil Dewey aplicada a las ciencias geológicas para la formación de la Bibliografía Geológica por el Servicio Geológico de Bélgica».

48 CLASIFICACIÓN Decimal de Melvil Dewey para bibliotecas. Tablas generales compendiadas Traducción de Fernando Ferrari Pérez y Maximiliano M. Chaubert. México, Oficina Tipográfica de la Secretaría de Fomento, 1900.

49 A.B.N., Fondo Universidad, Expediente 4 (II), 1899.

50 Loc. cit., 18 de diciembre de 1899. 
nense y el instituto liderado por Otlet, se inclinaba por la Clasificación Decimal de Dewey de manera convencida:

«No cabe duda que, hasta donde es posible, la de Dewey, es uno de los procedimientos analíticos que pueden emplearse con más éxito en una bibliografía internacional» ${ }^{51}$.

En 1912, la Secretaría de Comunicaciones y Obras Públicas introdujo la C.D.U. en su biblioteca, y extendió su uso a la formación de expedientes y archivos ${ }^{52}$. Esta secretaría intentó, sin éxito, que una comisión de especialistas de los Estados Unidos se trasladara a México para aplicar la Clasificación Decimal a su biblioteca y a la de Fomento. Finalmente, se llevó a cabo con el recurso a un catálogo alfabético de autores y de obras clasificadas por materias, elaborado ad hoc, sin relación alguna con la C.D.U.

En cuanto a la clasificación de los archivos, desde muy temprano las autoridades se decantaron por una clasificación decimal. Tanto la citada Secretaría de Comunicaciones y Obras Públicas, como la de Relaciones Exteriores, de Industria, Comercio y Trabajo y la de Gobernación desarrollaron toda una serie de publicaciones para la utilización de la clasificación decimal a la hora de archivar los asuntos y expedientes dependientes de las mismas. Una iniciativa que se extendió a los gobiernos de los diferentes estados de la República ${ }^{53}$.

La Biblioteca Nacional acometió la catalogación de sus fondos con el sistema mencionado de Namur bajo la dirección de José María Vigil ${ }^{54}$. Tras su fallecimiento en 1909, la dirección de la Biblioteca recayó en diversos personajes de la vida cultural de país, cuyos mandatos, excesivamente breves, imposibilitaron una reorganización de suficiente calado. Únicamente bajo la vinculación de Juan Bautista Iguíniz

51 GALINDO Y ViLlA, J. (1901), «La clasificación de los conocimientos humanos y la bibliografía»: Memorias de la Sociedad Científica Antonio Alzate, IV, 117-145. El autor insinuaba que el Instituto mexicano terminó utilizando la clasificación decimal de Dewey para catalogar los trabajos.

52 Cfr. Álvarez, M. F. (1920), Las Bibliotecas públicas y particulares. México, Secretaría de Gobernación [Sobretiro de los Anales de la Secretaría de Comunicaciones y Obras Públicas, II, 87-105]. Se trata de la obra Instrucciones sumarias para la clasificación decimal de los asuntos que tenga a su cargo el oficial encargado del recibo y apertura de la correspondencia. A cargo de Ezequiel A. Chávez. México, Talleres Tipográficos de la Secretaría de Comunicaciones y Obras Públicas, 1912.

53 CHÁveZ, E. A. (1912), Secretaría de Comunicaciones y Obras Públicas. Instrucciones sumarias para la clasificación decimal de los asuntos que tenga a su cargo el oficial encargado del recibo y apertura de la correspondencia, México, Talleres tip. de la Secretaría de Comunicaciones y Obras Públicas; Lombardo, V. (1922), Secretaría de Educación Pública. Tablas generales compendiadas del sistema decimal "Melvil Dewey" para bibliotecas, con las modificaciones introducidas en él por el Instituto Internacional de Bibliografía de Bruselas, México, Dirección de Talleres Gráficos.

54 Nacido en 1829 en Guadalajara estudió latinidad, filosofía y jurisprudencia, no llegó a terminar la carrera de leyes atraído por la literatura y el periodismo desde donde defendió sus convicciones liberales. Fue diputado, tras el triunfo de la República, y director de la Biblioteca Nacional desde 1880 hasta su muerte en 1909. 
(sucesivamente subdirector, 1917-1926 y 1941-1946, jefe de la sección de Bibliografía, 1937-1941, director auxiliar, 1947-1951, y finalmente director, 1951-1956), se logró acometer un cambio del método clasificatorio, adoptando la clasificación decimal de Dewey. Este bibliógrafo publicó, en 1919, las Instrucciones para la redacción y formación de los catálogos bibliográficos según el sistema de Melvil Dewey, adaptadas a las bibliotecas hispano-americanas, en las que se basaron para su recatalogación. Así mismo, sustituyó paulatinamente los catálogos de libros por cédulas bibliográficas y echó a andar el catálogo onomástico y el catálogo diccionario.

\section{EPÍlOGO}

La incorporación de los países periféricos a los desarrollos de la ciencia contemporánea exige un análisis detallado de cada uno de ellos. Las condiciones sociopolíticas y culturales de cada entorno nacional matizó y condicionó esa asimilación. En el caso de México, su participación en el proyecto documental apadrinado por la Royal Society de Londres tuvo más que ver con el intento de dinamizar la propia ciencia local al servicio de un proyecto político concreto, el porfiriato, y utilizarlo como escaparate exterior de los logros nacionales, que con las necesidades documentales de la comunidad científica mexicana. El caso chileno presenta, como hemos señalado en otro trabajo, unos matices bien diferentes. La colaboración de Chile con el Instituto Internacional de Bibliografía de Bruselas se debió a una sentida necesidad de organización interna del saber y de los recursos bibliográficos, exenta, en buena medida, del componente publicista que animó a la participación mexicana. 